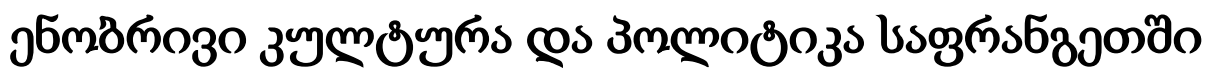

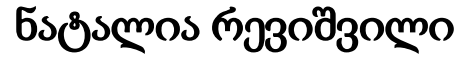

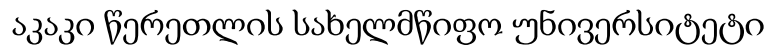 \\ e-mail: revishvilinatalia17@gmail.com
}

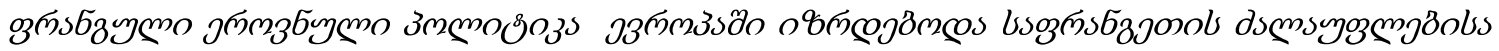

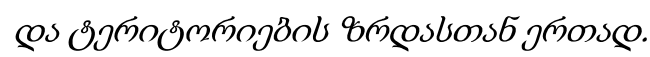

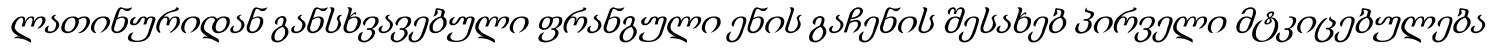

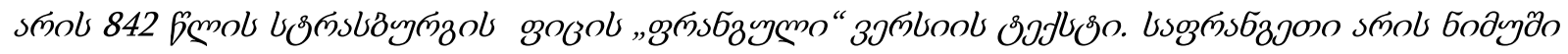

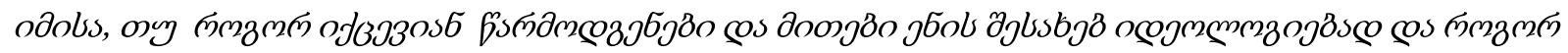

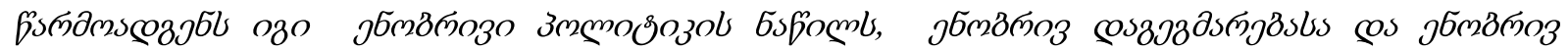

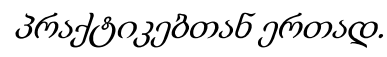

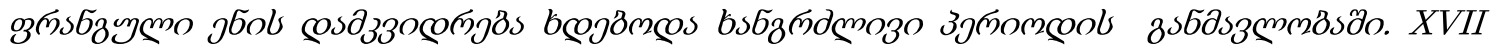

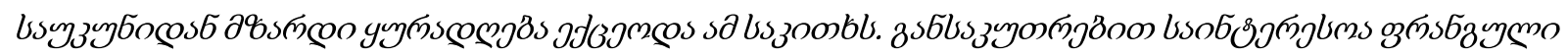

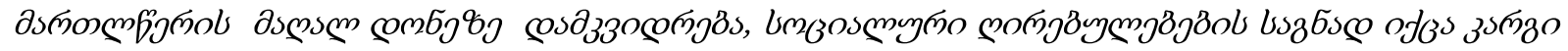

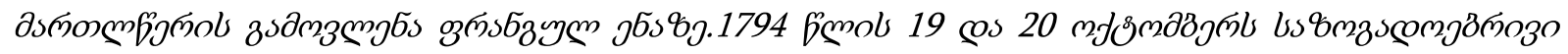

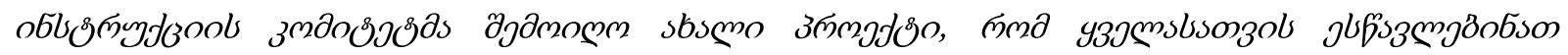

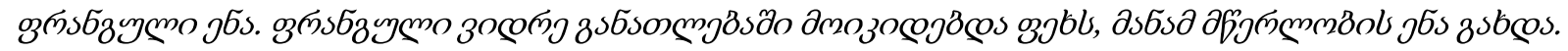

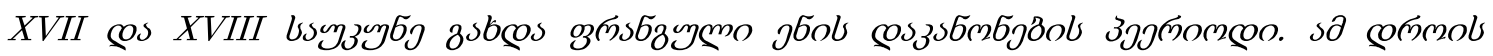

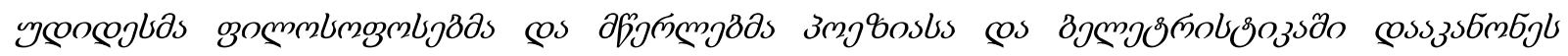

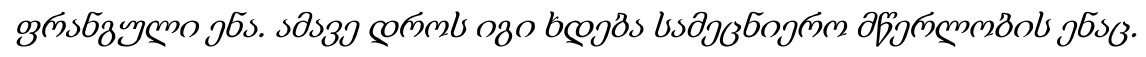

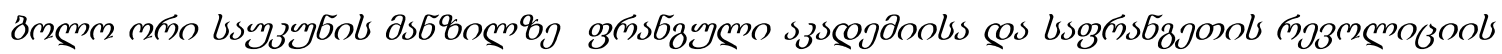

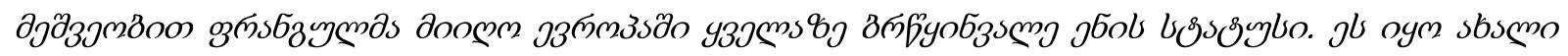

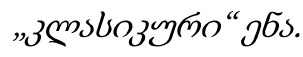

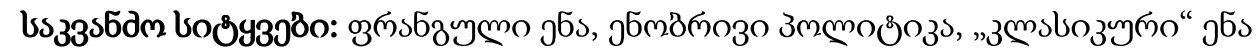

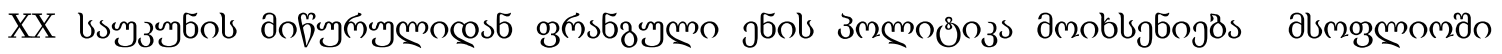

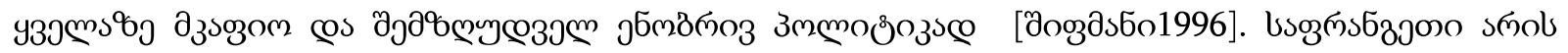

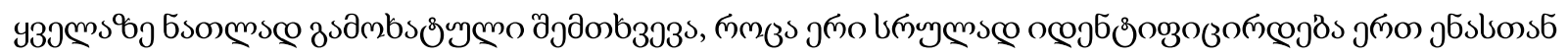

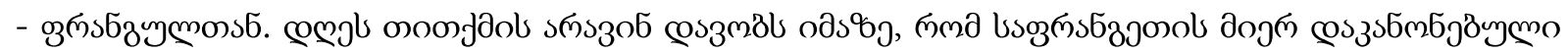

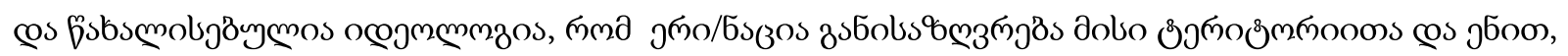

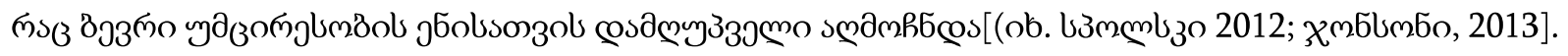

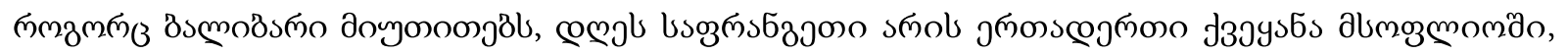

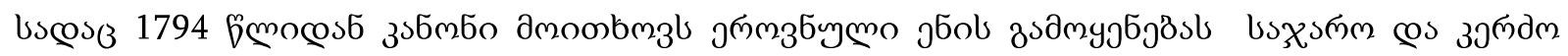

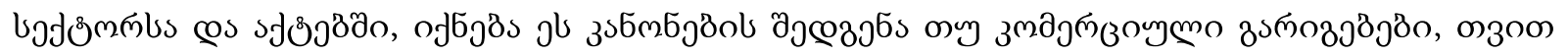

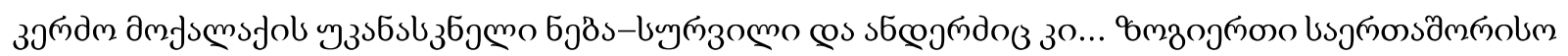




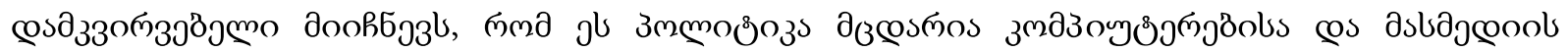

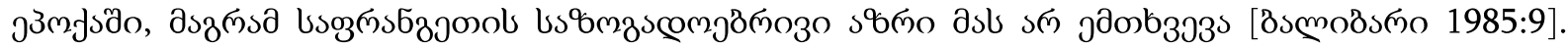

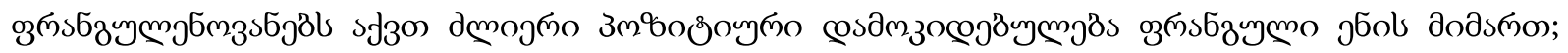

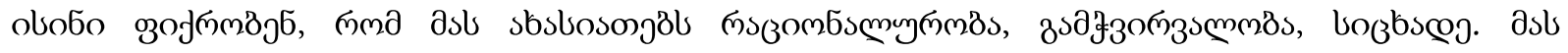

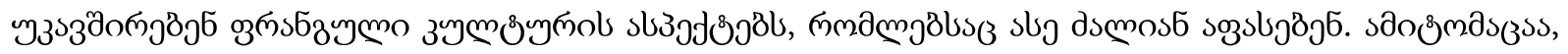

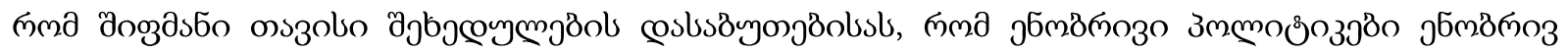

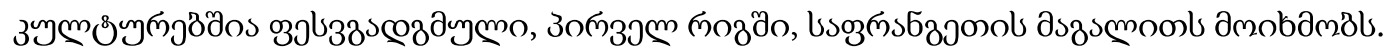

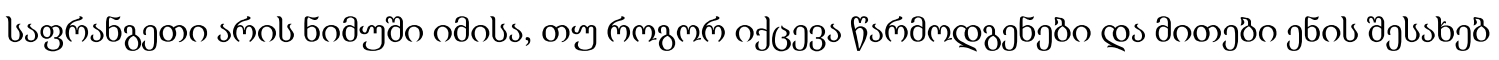

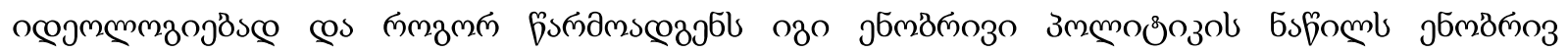

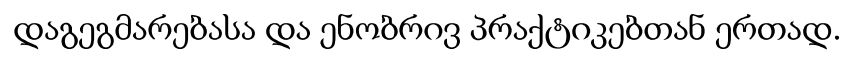

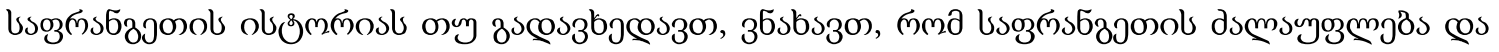

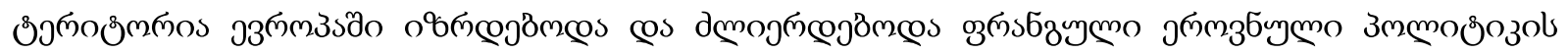

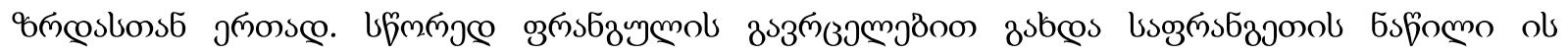

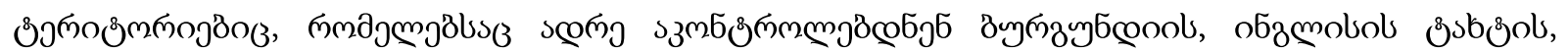

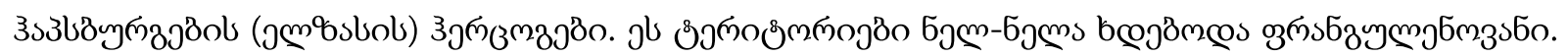

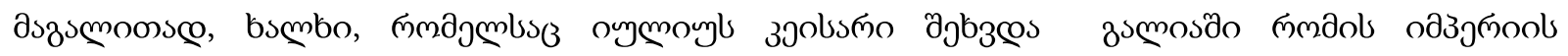

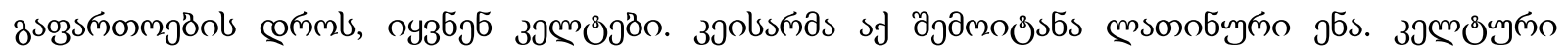

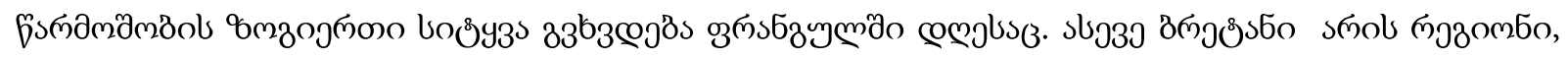

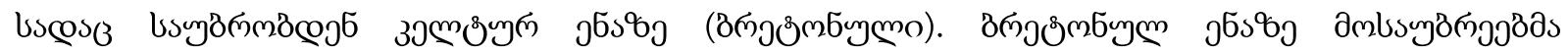

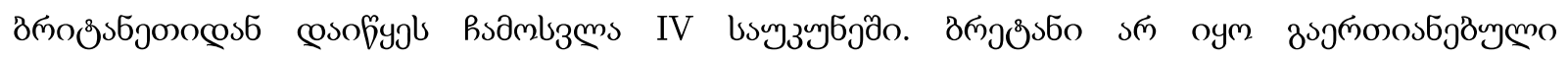

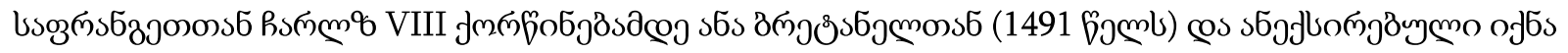

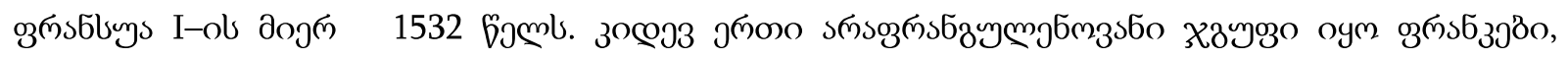

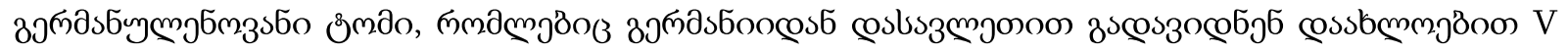

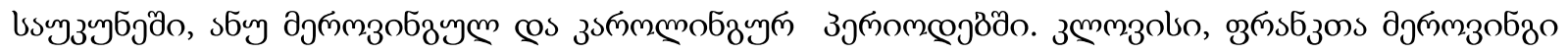

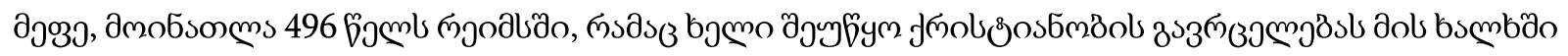

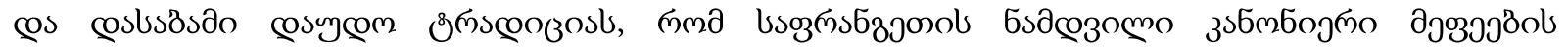

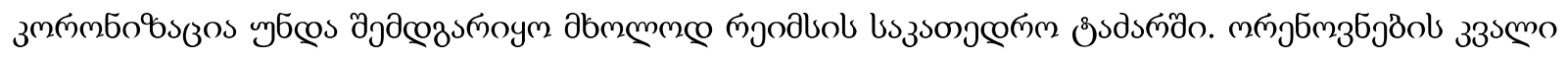

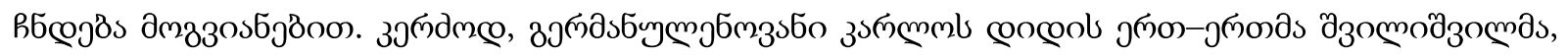

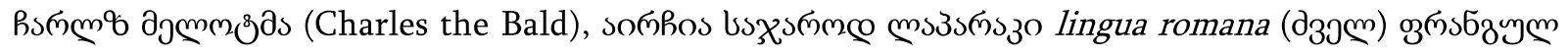

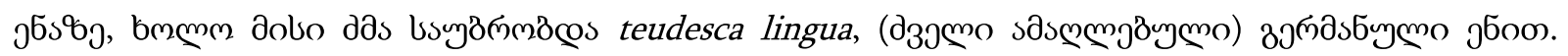

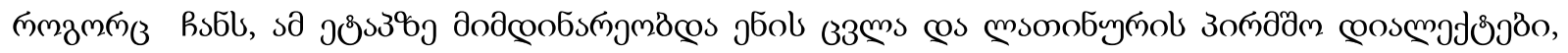

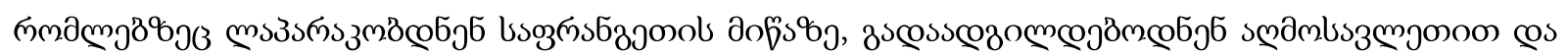

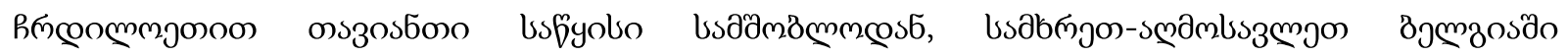

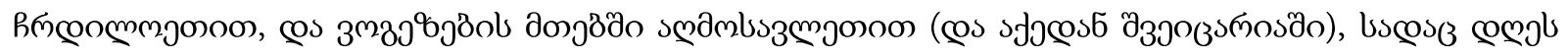

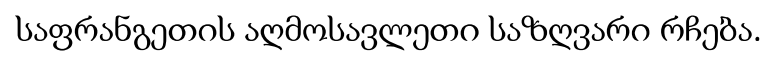

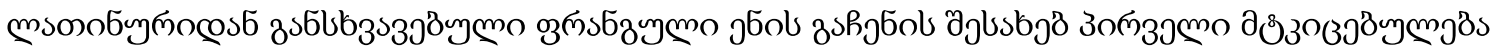

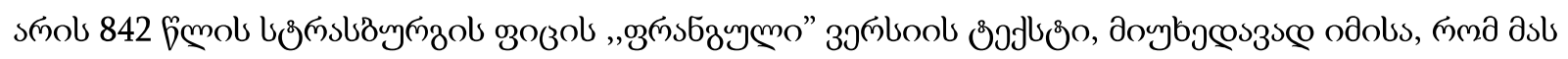

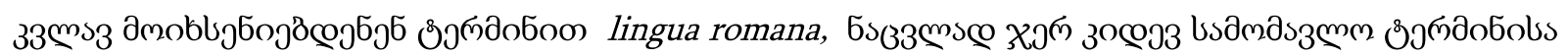

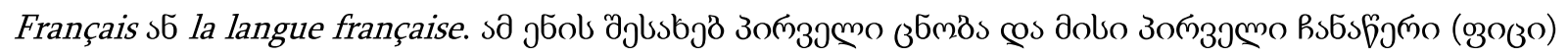

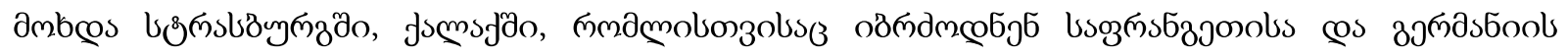

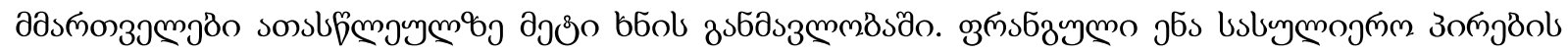

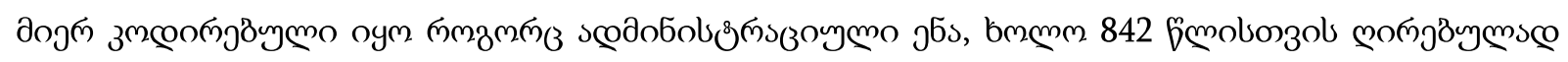

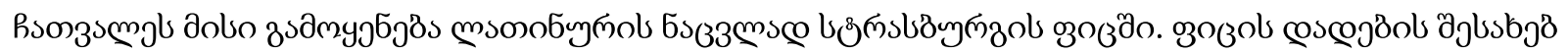




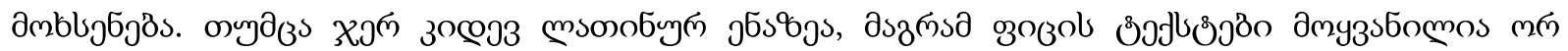

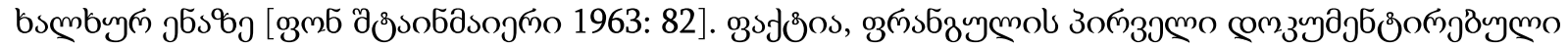

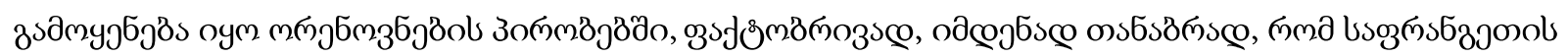

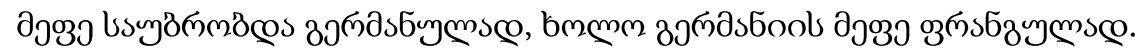

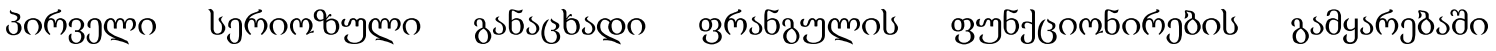

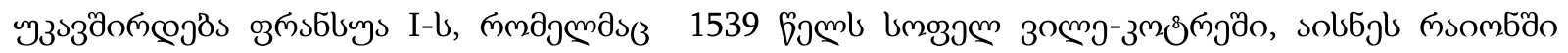

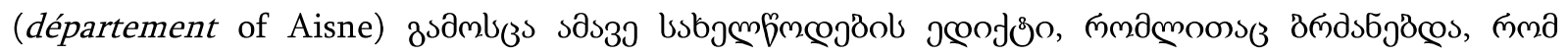

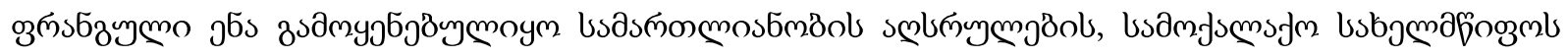

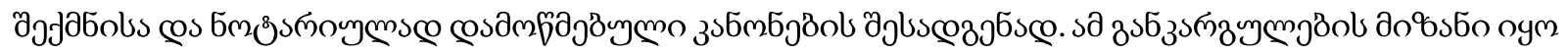

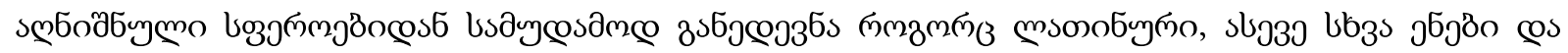

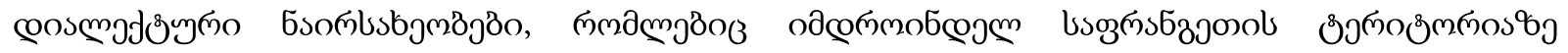
зsдмоујбјд̈м⿻s.

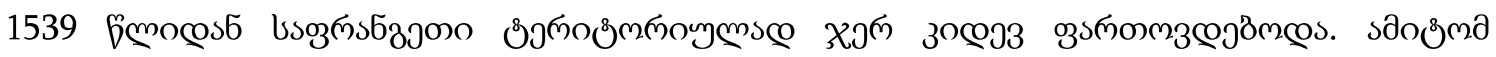

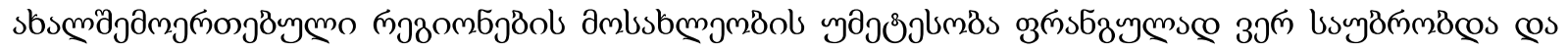

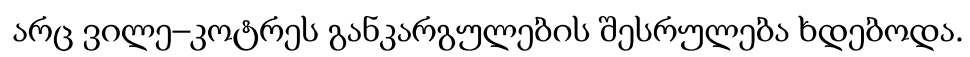

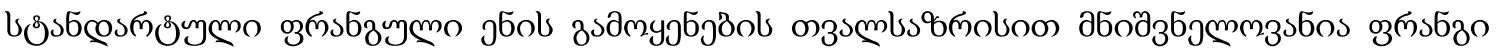

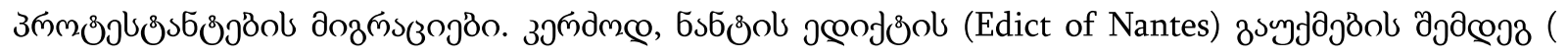

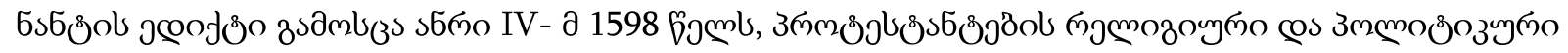

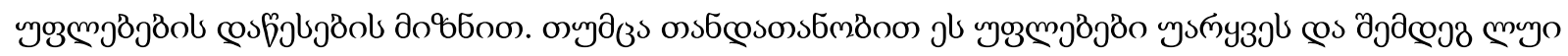

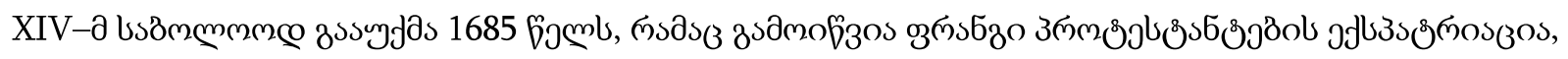

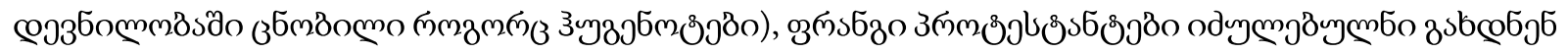

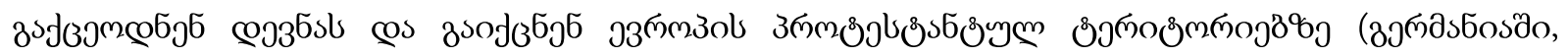

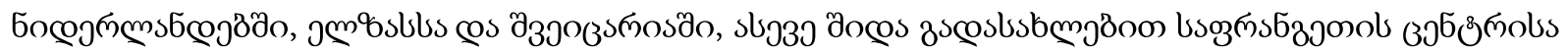

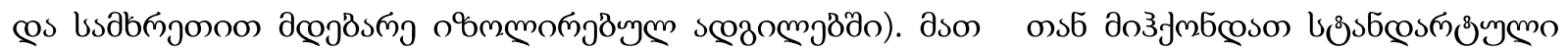

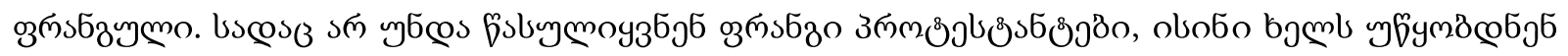

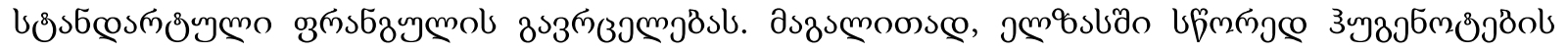

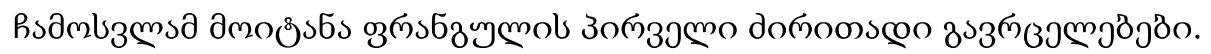

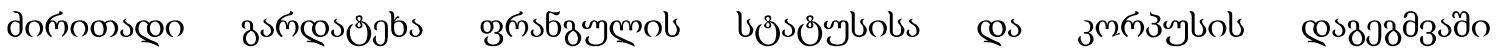

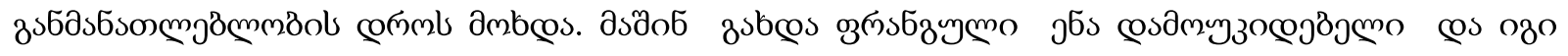

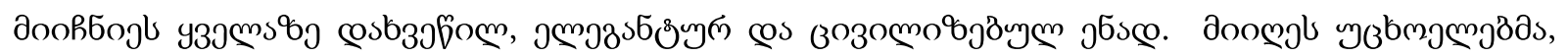

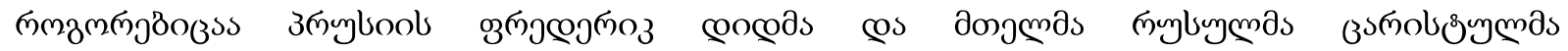

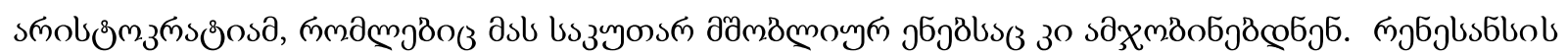

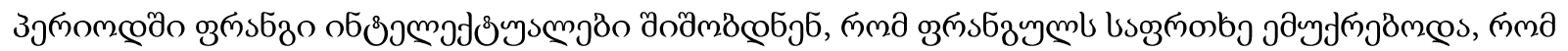

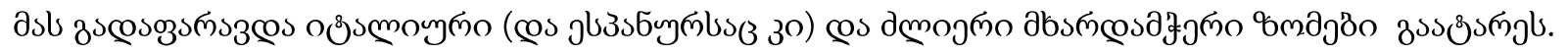

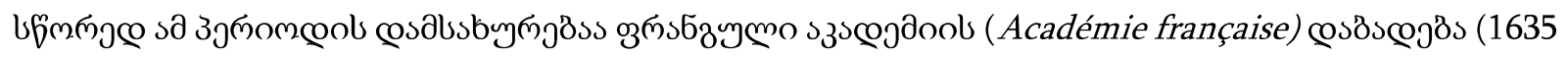

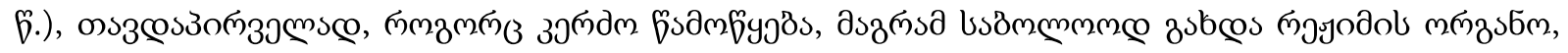

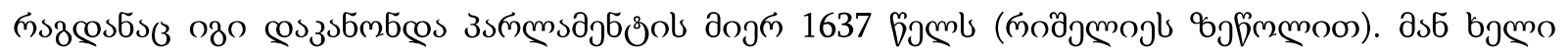

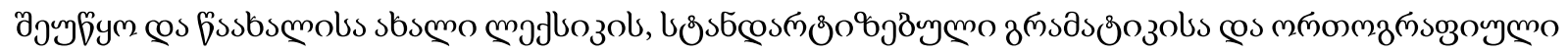

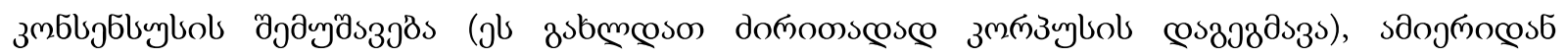

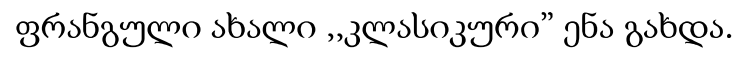

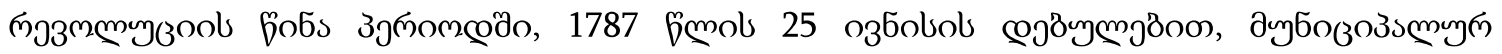

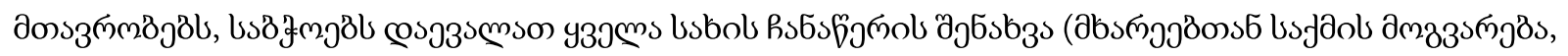

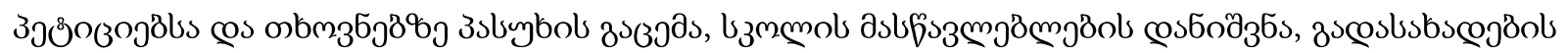




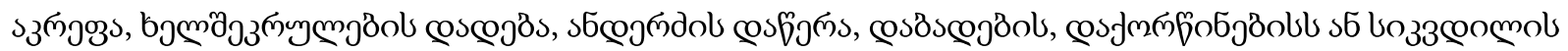

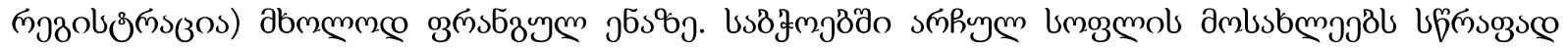

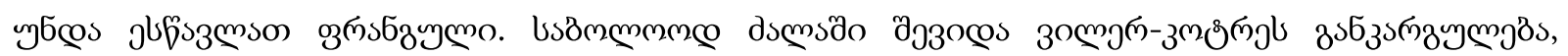

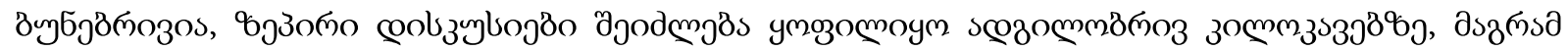

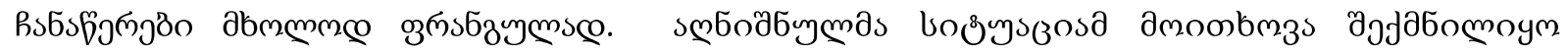

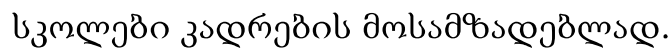

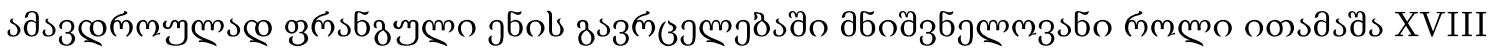

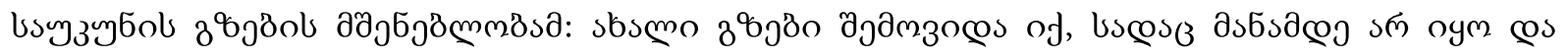

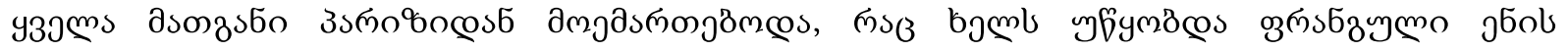

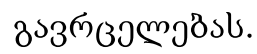

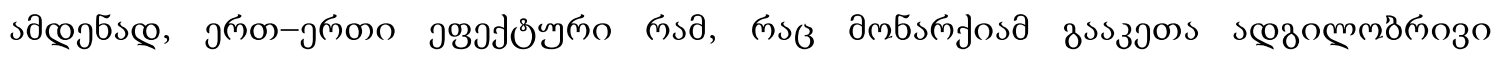

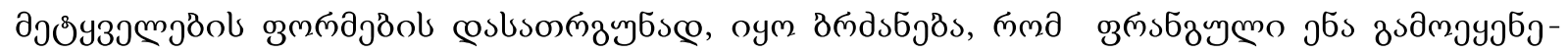

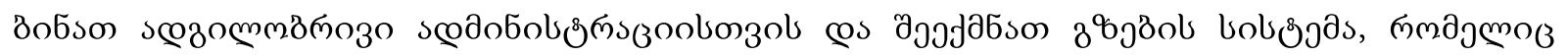

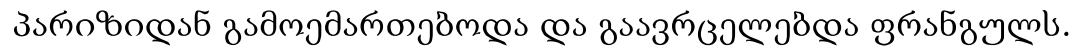

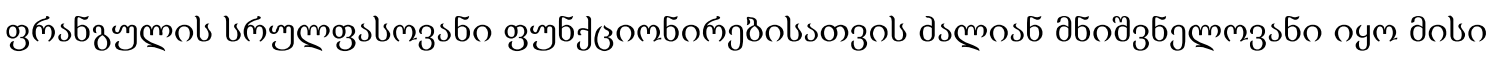

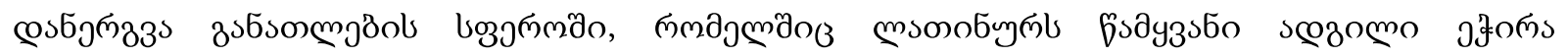

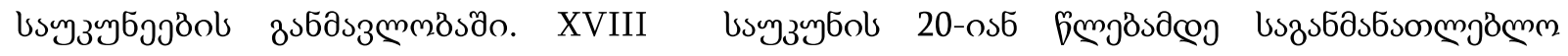

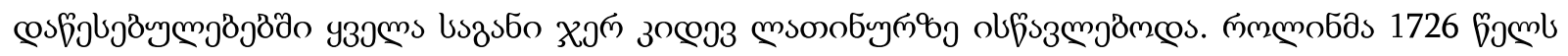

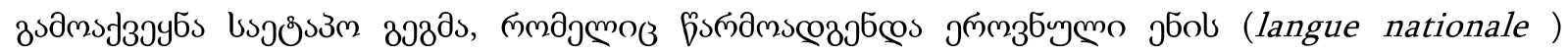
бృ

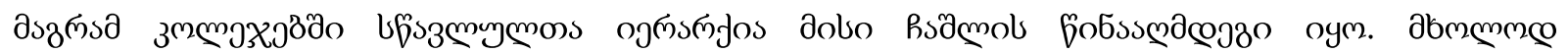

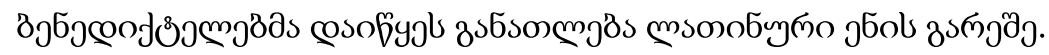

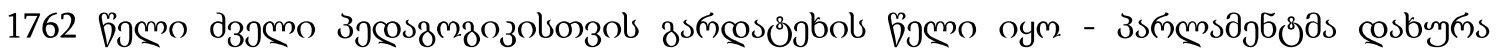

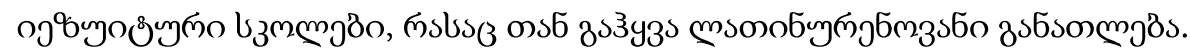

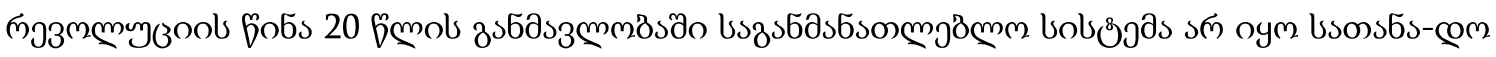

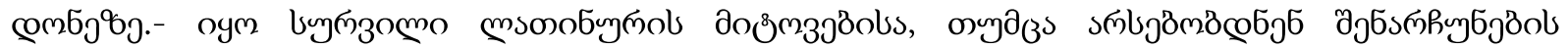

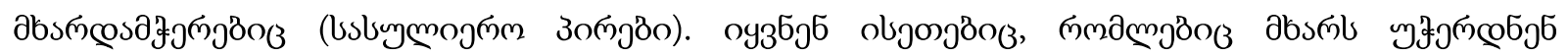

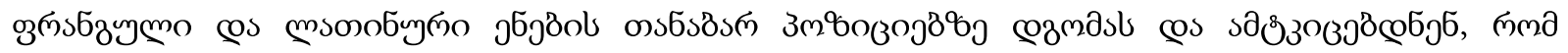

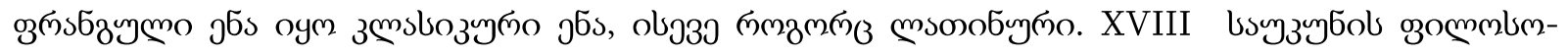

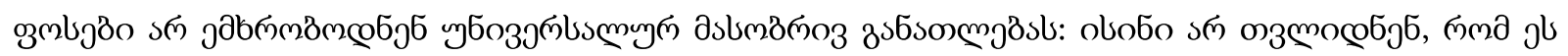

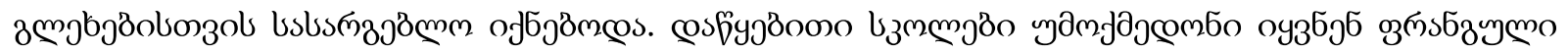

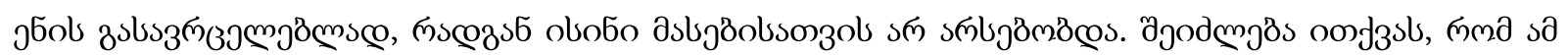

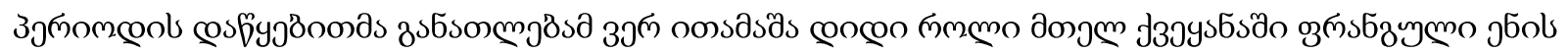

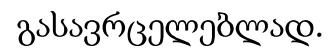

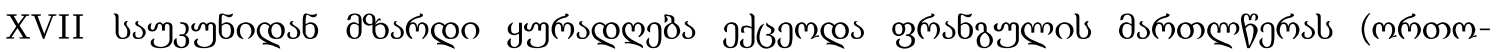

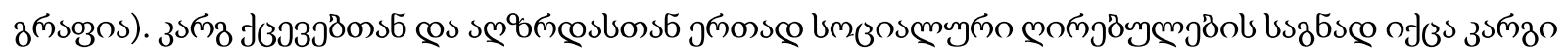

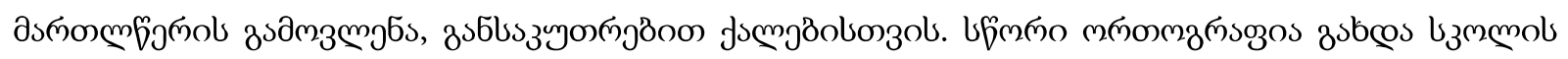

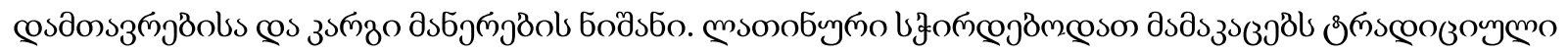

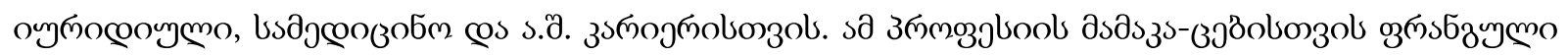

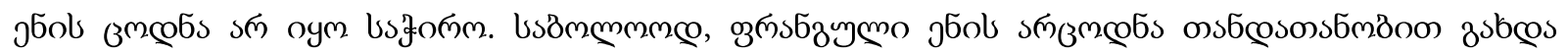
bsmojno gas bsognomb.

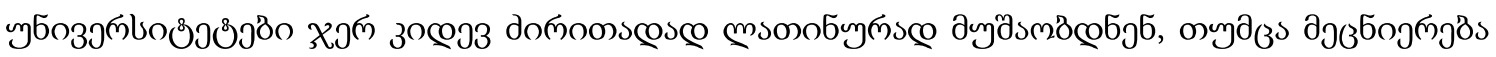

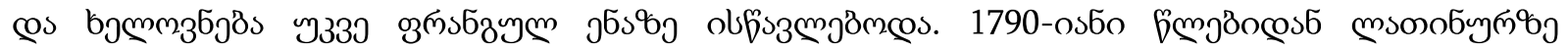




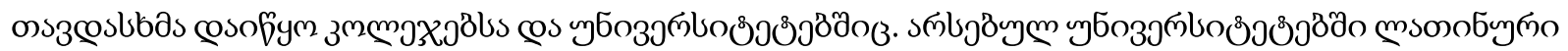

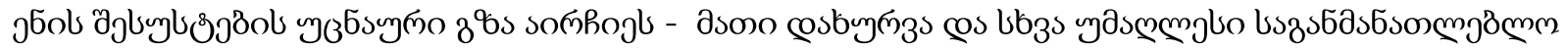

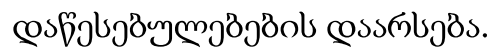

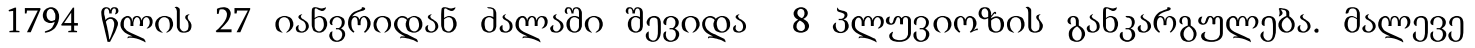

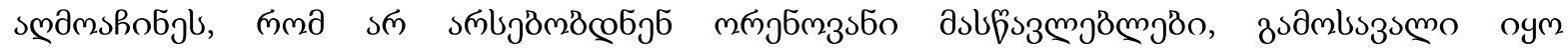

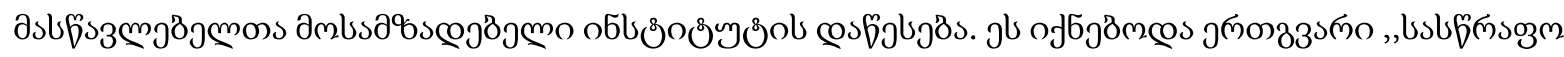

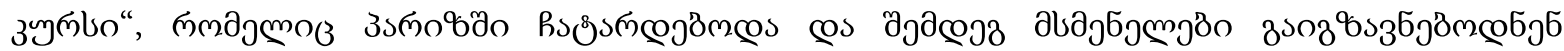

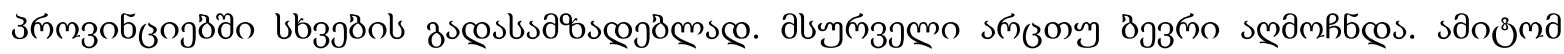

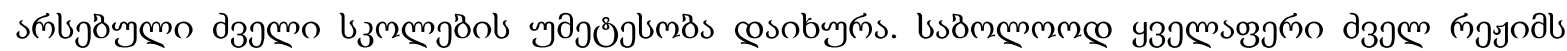

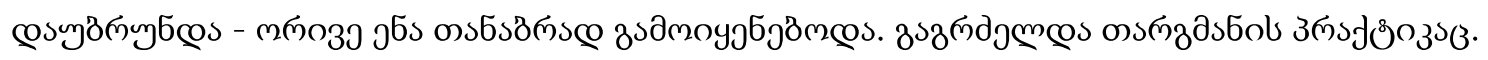

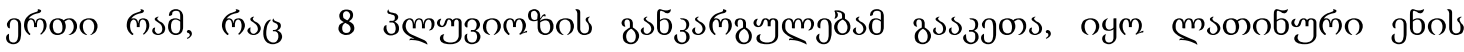

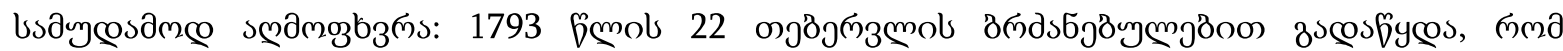

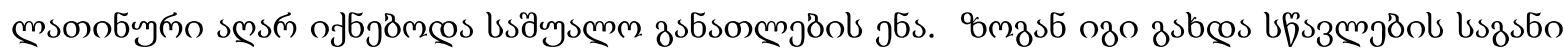

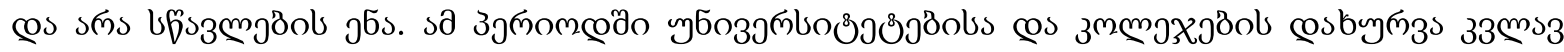

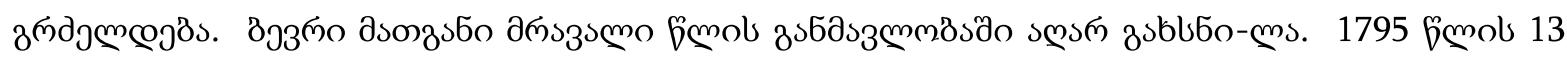

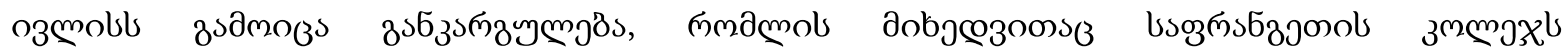

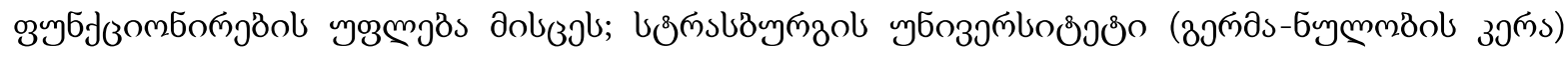

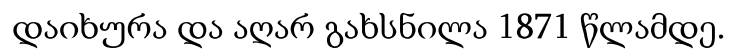

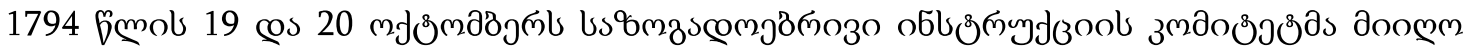

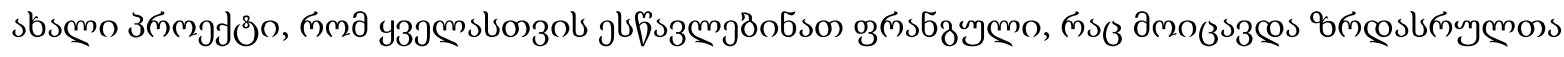

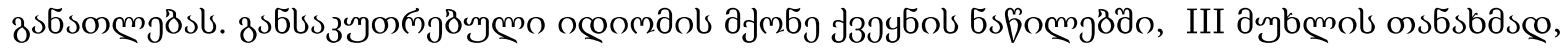

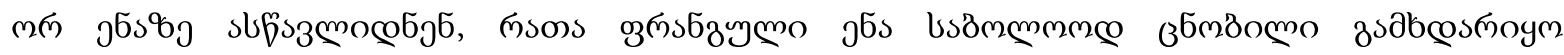

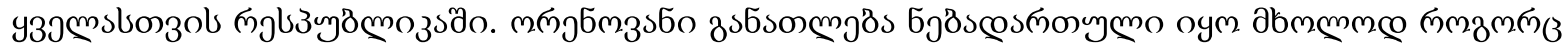

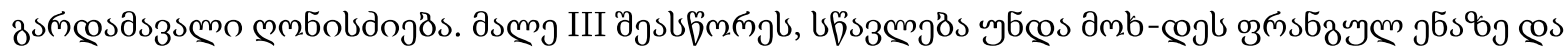

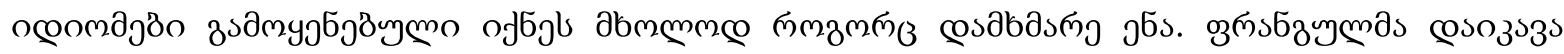

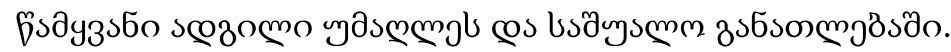

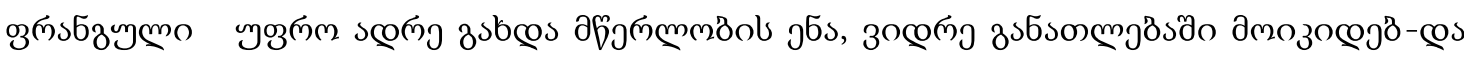

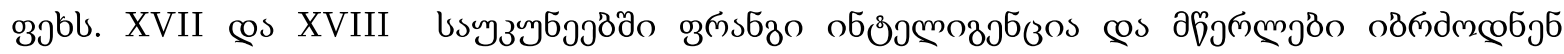

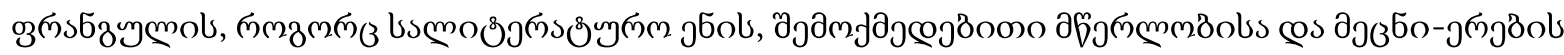

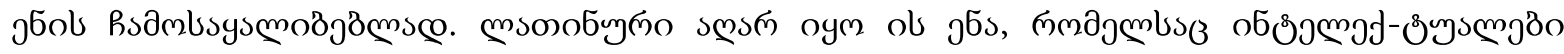

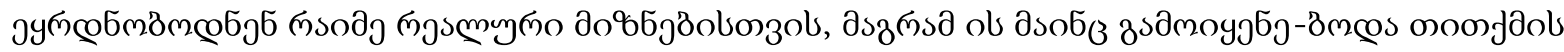

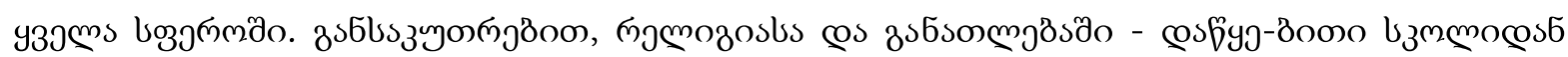

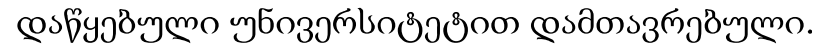

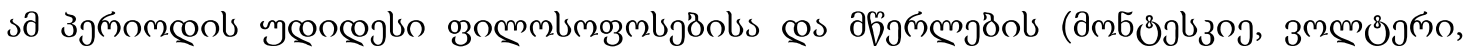

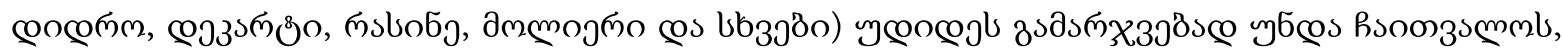

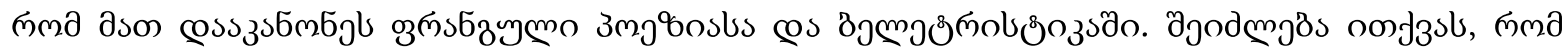

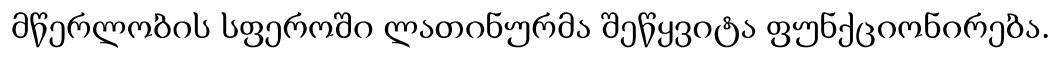

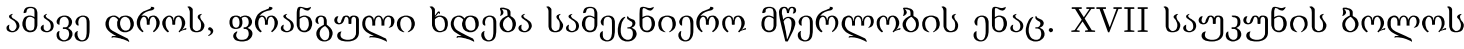

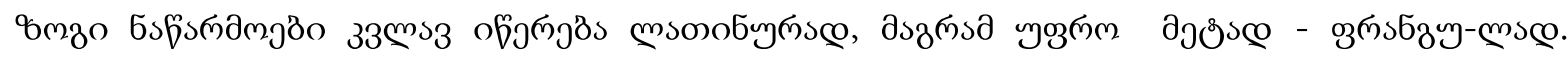

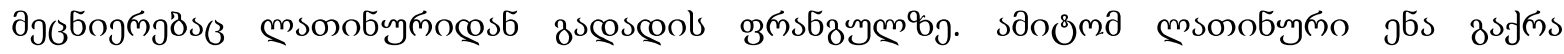

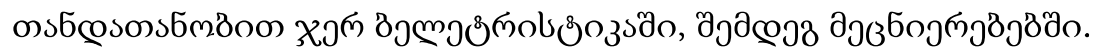

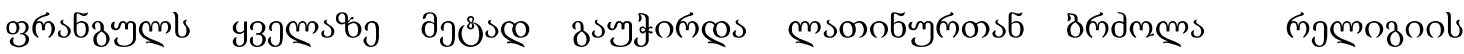

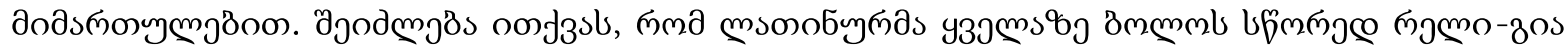




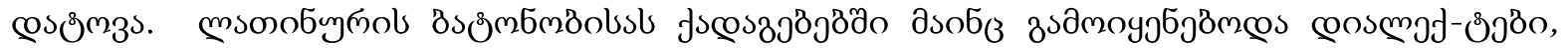

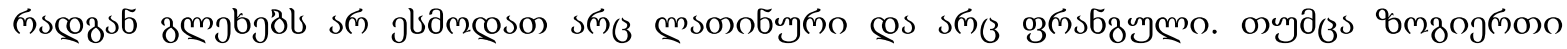

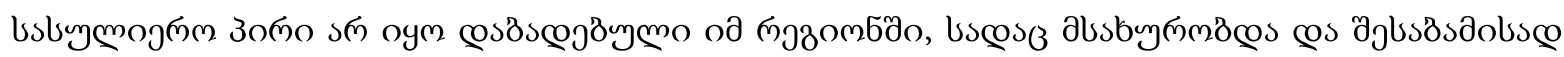

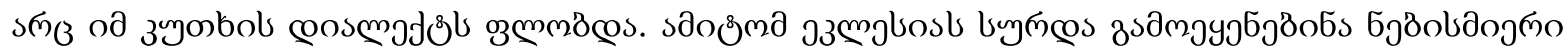

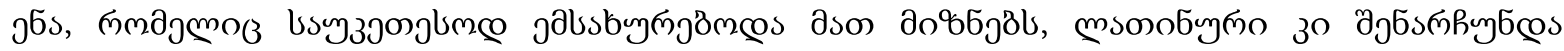

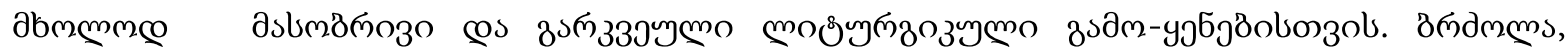

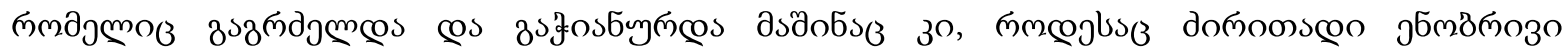

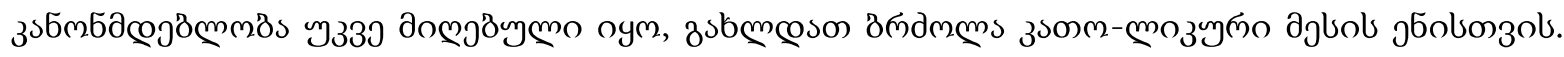

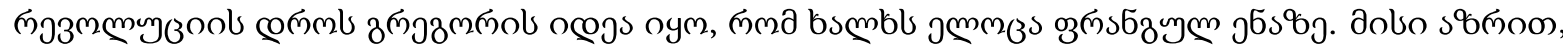

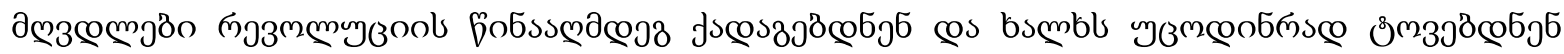

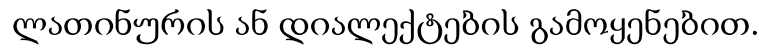

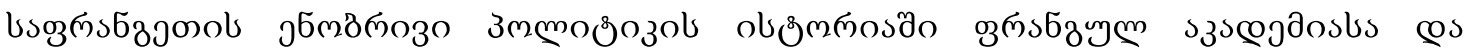

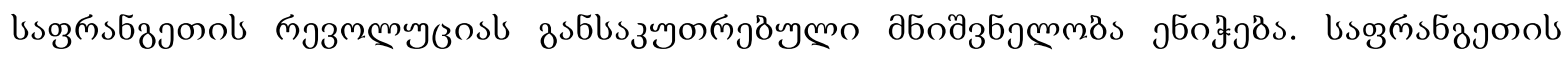

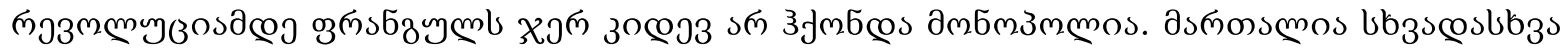

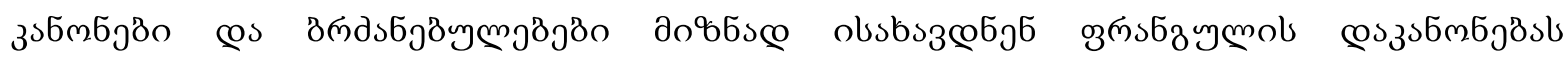

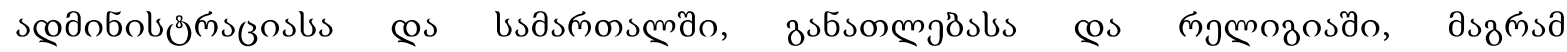

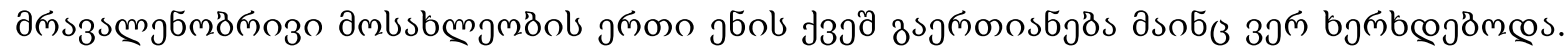

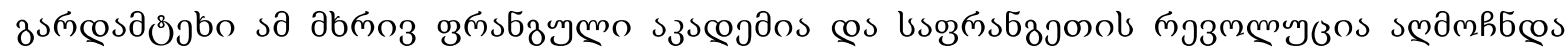

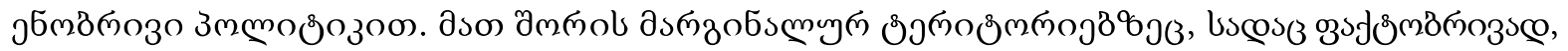

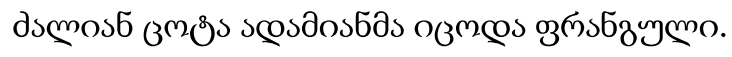

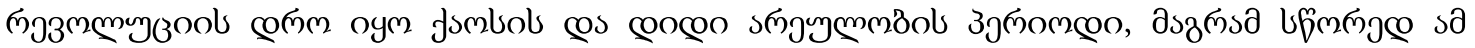

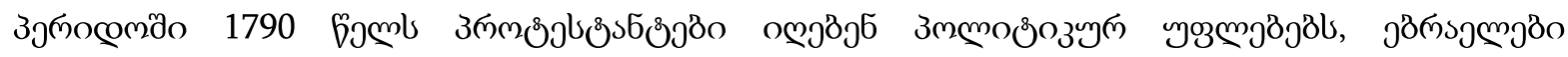

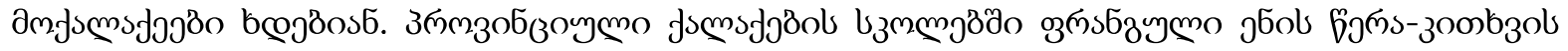

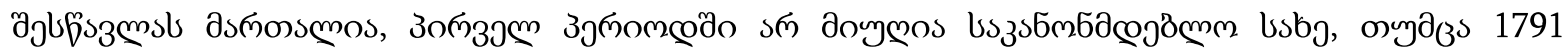

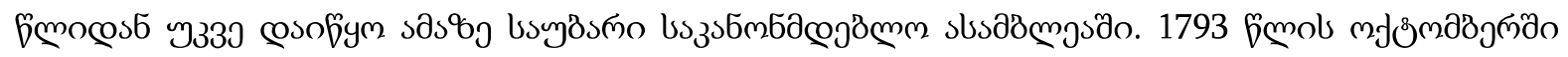

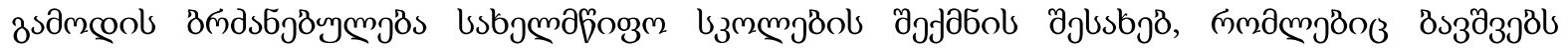

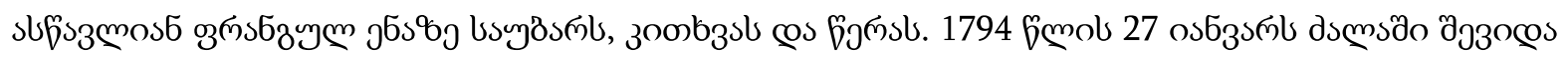

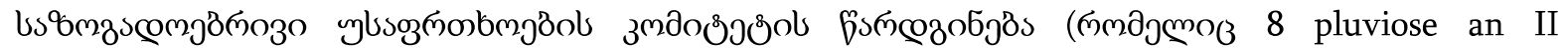

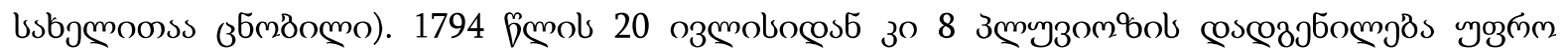

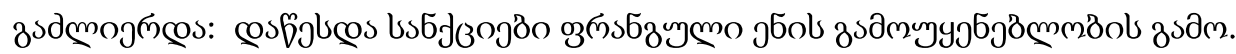

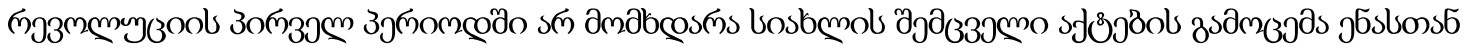

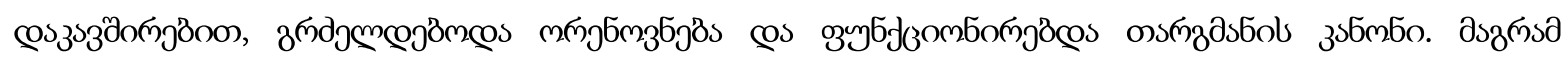

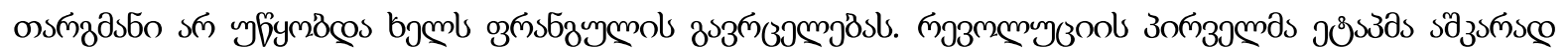

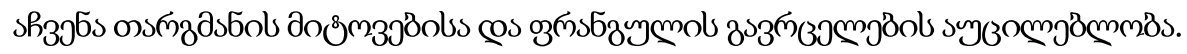

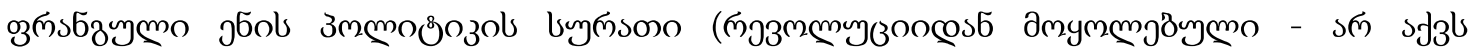

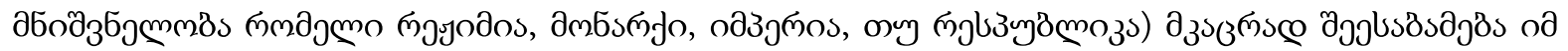

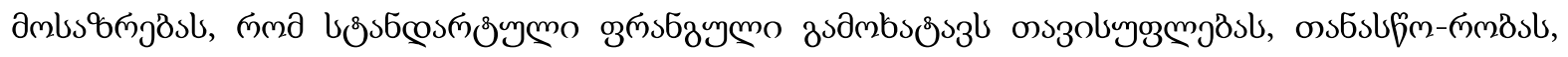

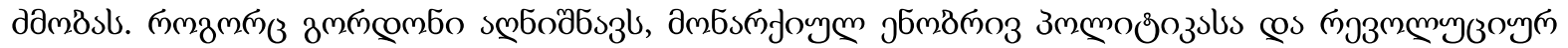

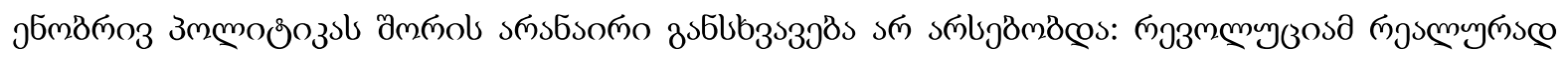

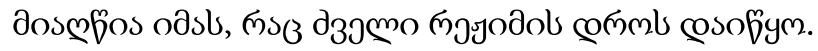

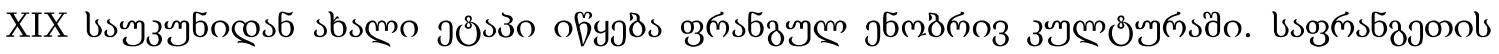

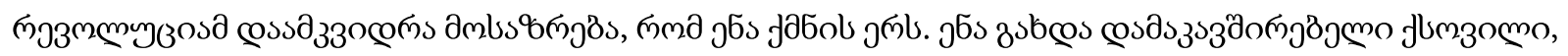

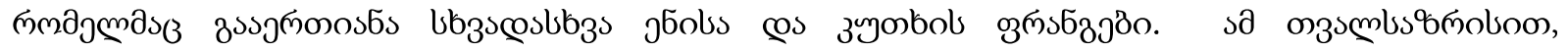




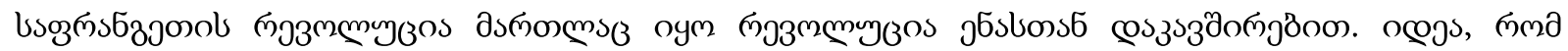

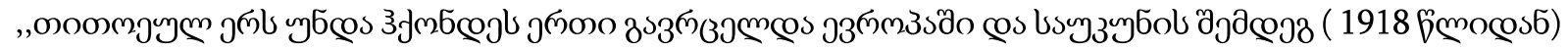

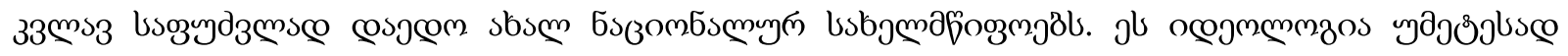

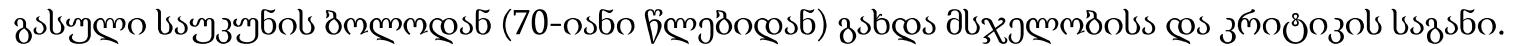

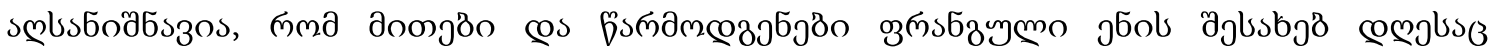

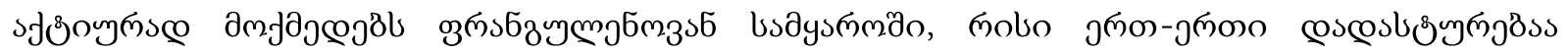

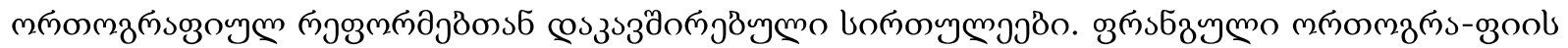

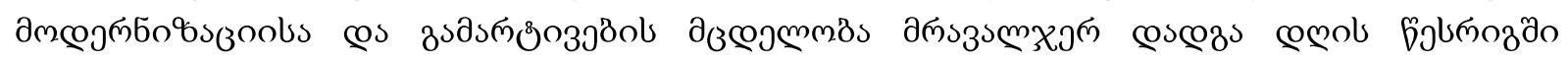

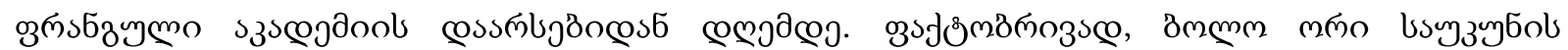

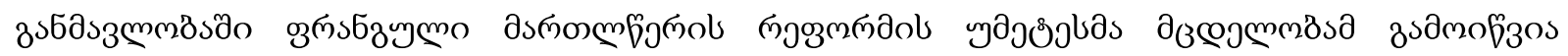

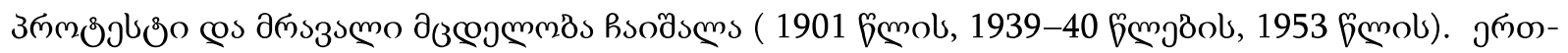

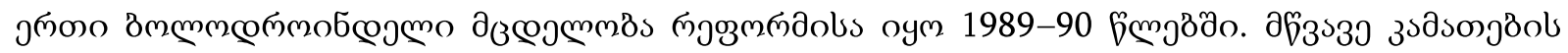

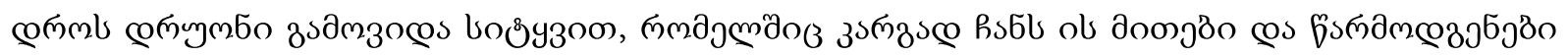

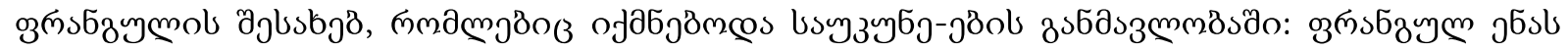

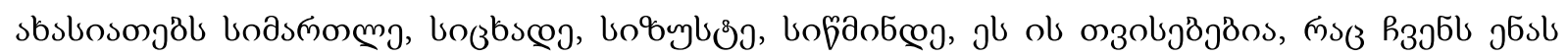

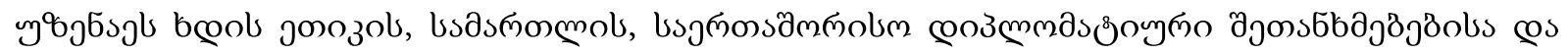

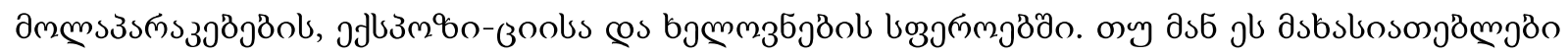

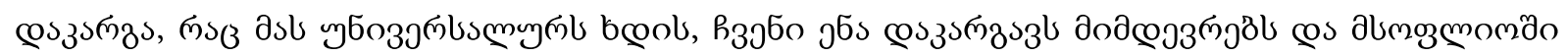

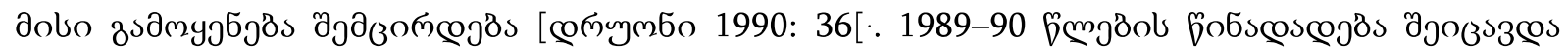

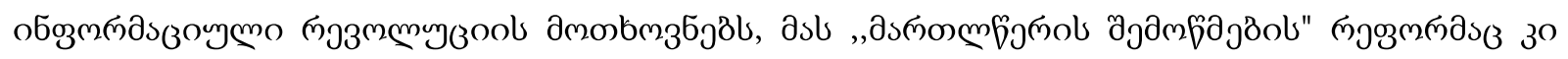

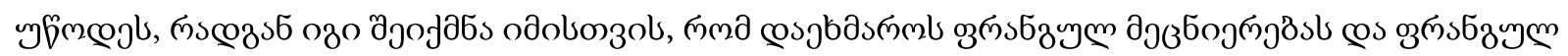

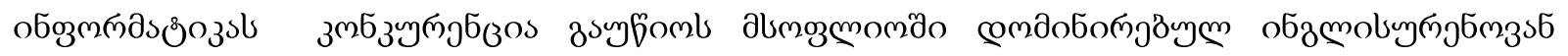

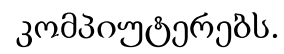

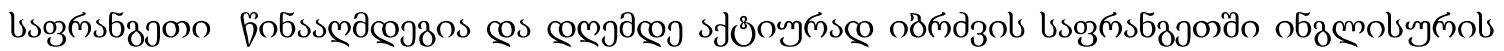

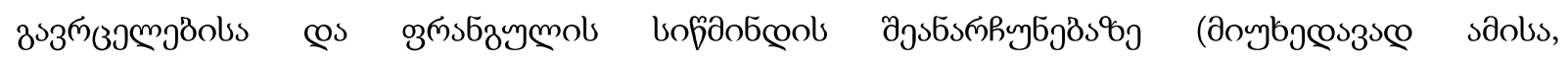

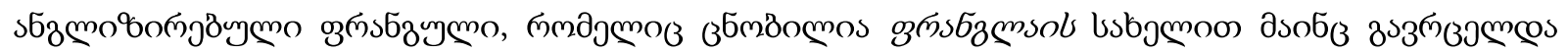

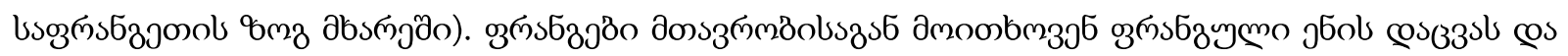

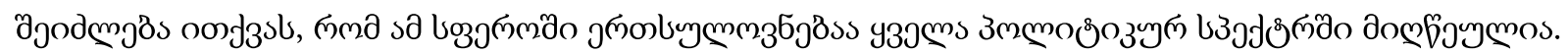

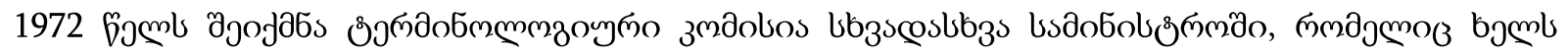

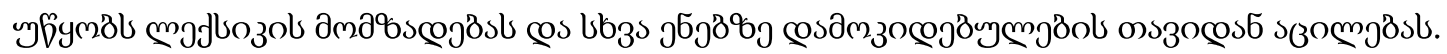

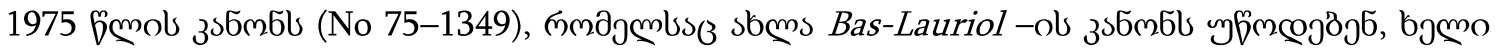

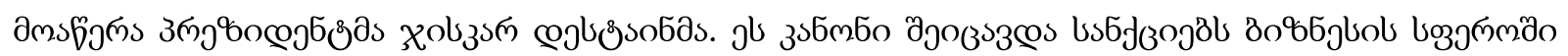

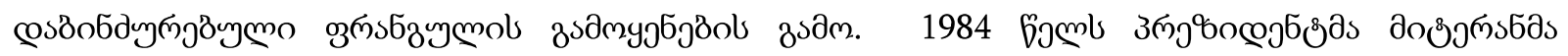

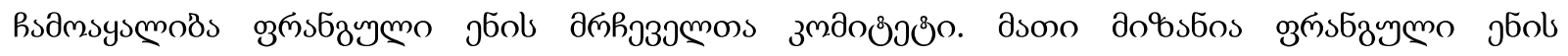

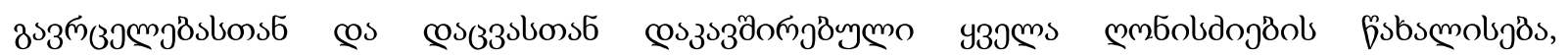

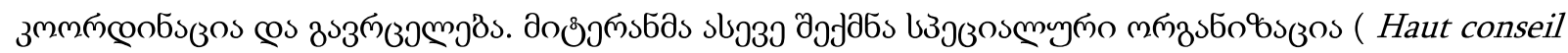

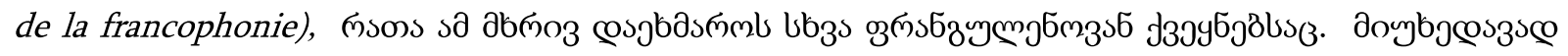

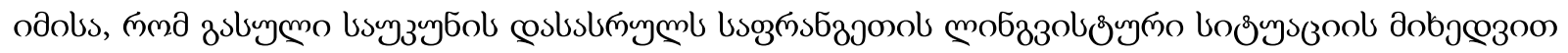

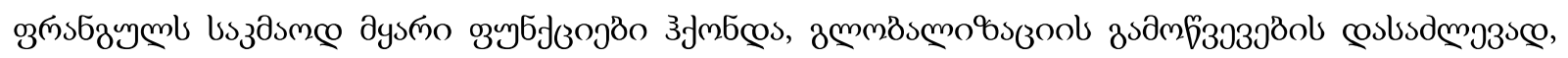

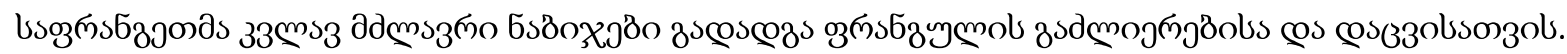

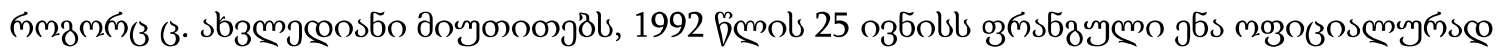

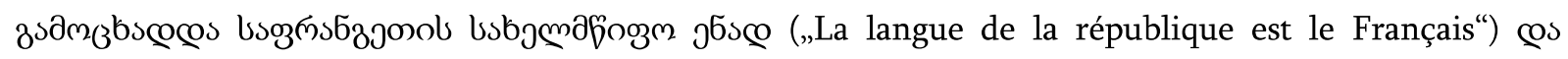

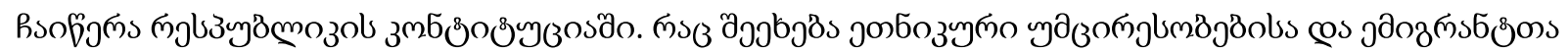




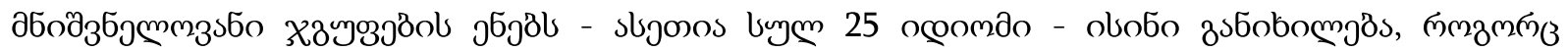

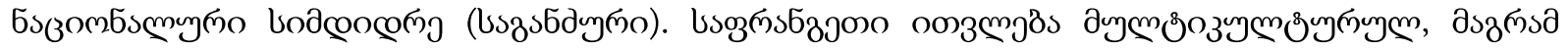

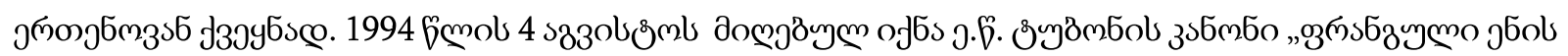

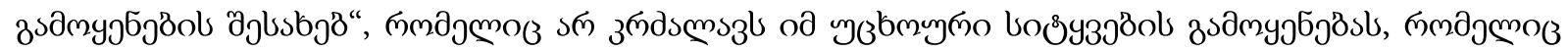

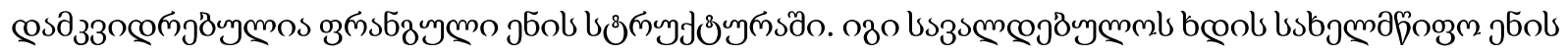

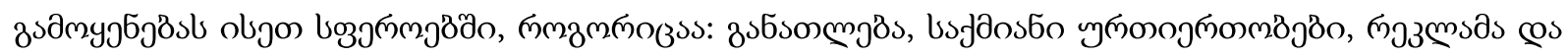

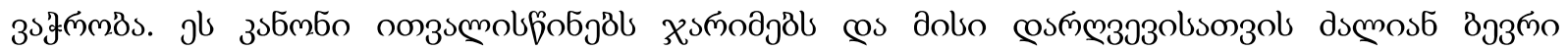

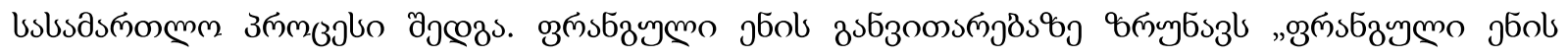

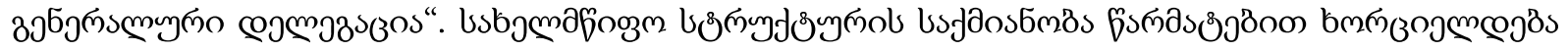

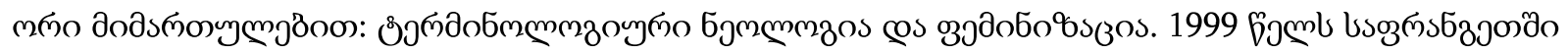

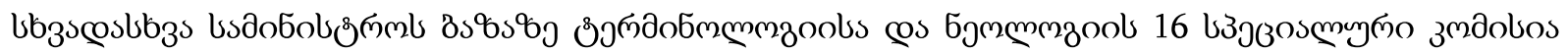

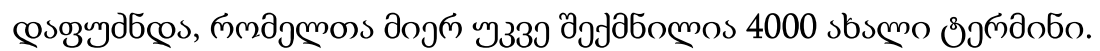

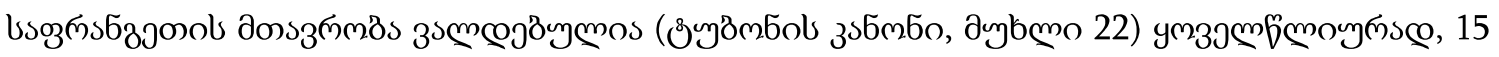

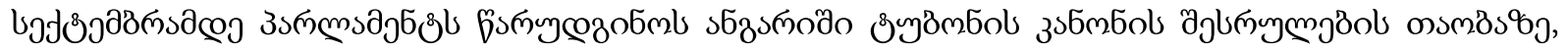

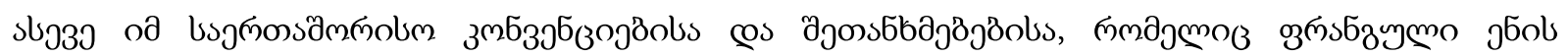

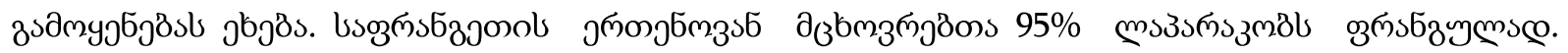

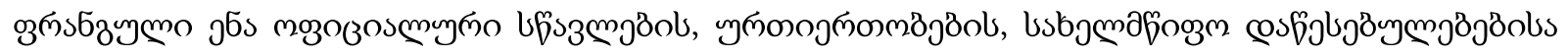

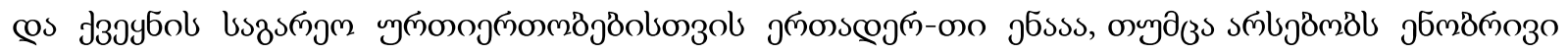

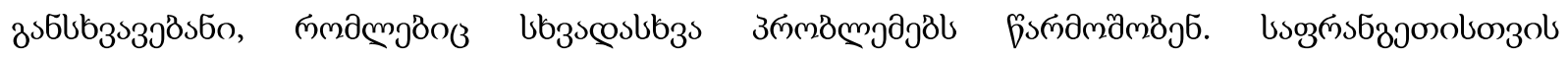

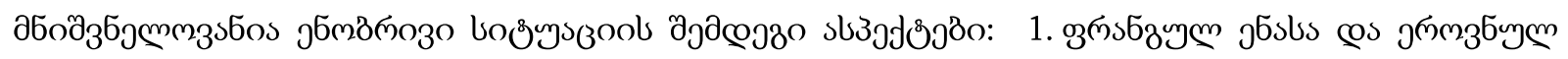

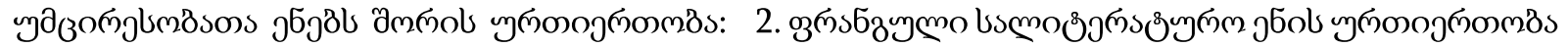

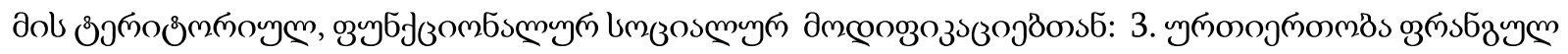

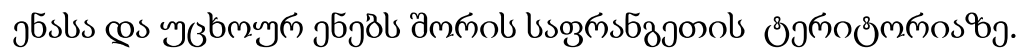

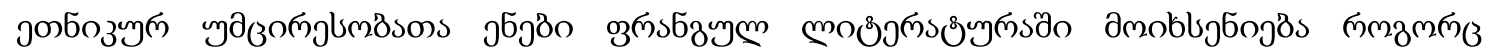

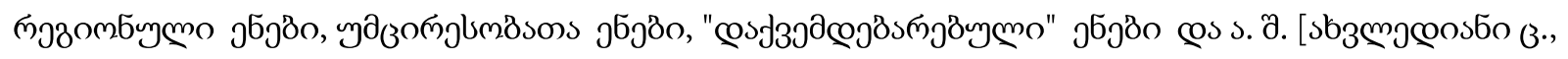
2006 ตэмо:.21].

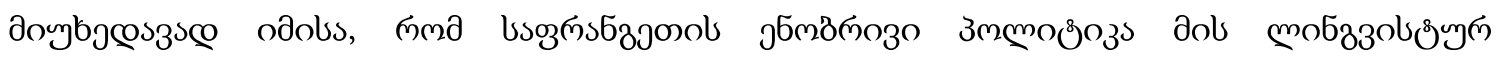

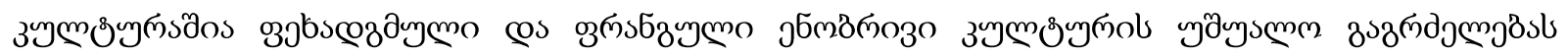

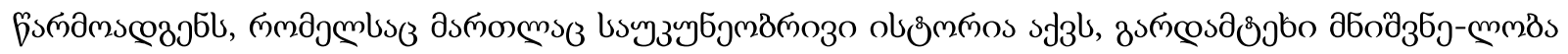

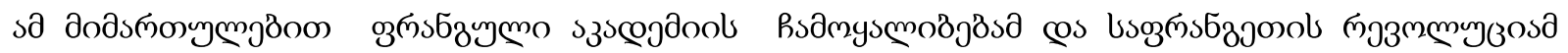

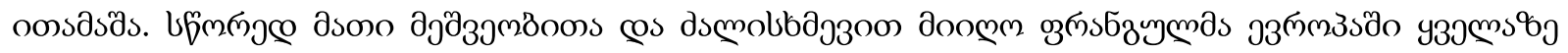

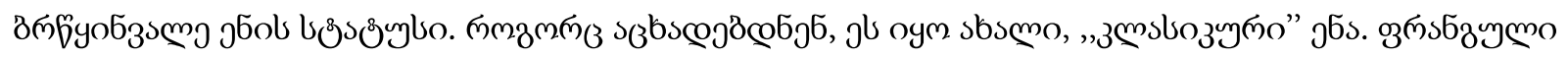

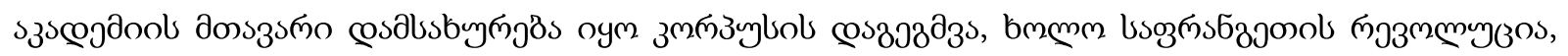

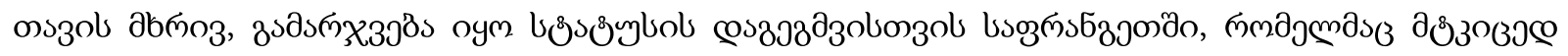

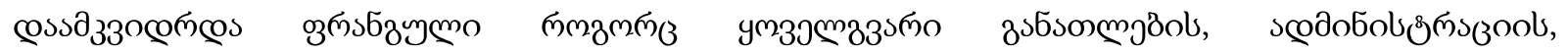

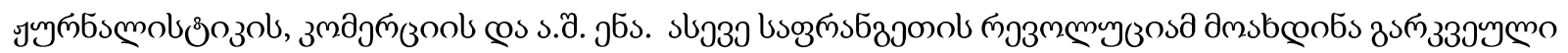

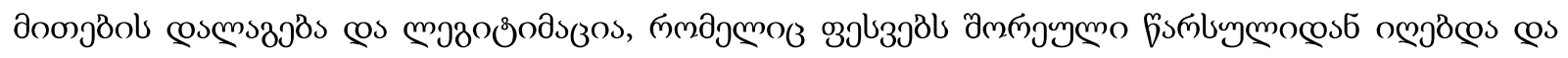

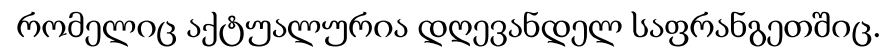




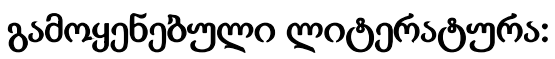

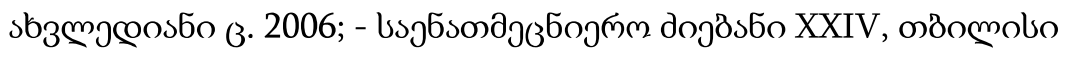

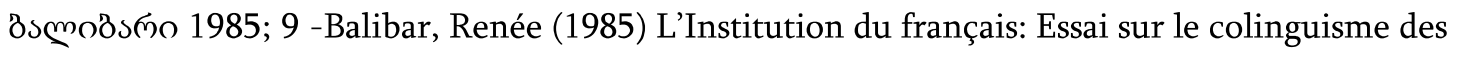
Carolingiens a la république. Presses Universitaires de France, Paris

b3mmbzo 8. 2012; -The Cambridge Handbook of Language Policy, Edited by Bernard Spolsky, First published (2012), Camb

Øoogas6o 3. 1996; -Harold F. Schiffman (1996). Linguistic Culture and Language Policy, London and NY: Routledge

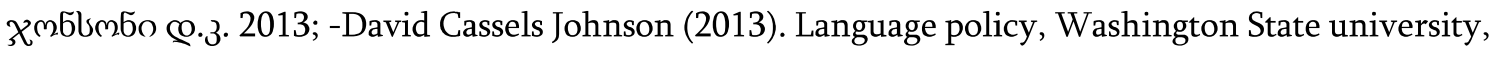
Palgrave macmillan

\section{Linguistic culture and politics in France}

\section{Natalia Revishvili}

\section{Abstract}

The rise of the French national politics was taking place simultaneously with the rise of the French power and territories in Europe. The first evidence of the emergence of the French language distinguished from Latin is the text of the "French" version of the 842-nd Strasbourg Oath. France is an example of how ideas and myths about a language become ideologies and how it forms a part of a language policy, along with language planning and language practices.

The French language was being established over a long period of time. From the 17th century onwards, increasing attention was paid to this issue. It is especially interesting to establish a high level of French spelling, the expression of good spelling in the French language has become an object of social values. On October 19 and 20, 1794, the Public Instruction Committee introduced a new project to teach French to all. French became the language of writing before it set foot in education.

The 17-th and 18-th centuries became a period of legalization of the French language. The greatest philosophers and writers of this time legalized the French language in poetry and fiction. At the same time, it became the language of scientific writing. French gained the status of the most brilliant language in Europe over the last two centuries through the French Academy and the French Revolution. It was a new "classical" language.

Key words: Franch, linguistic policy; "classical“ language.

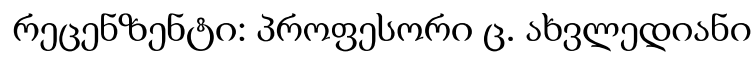

